\title{
"I want to be a nurse!": A Qualitative Descriptive Study on the Impact of an "Introduction to Nursing" Course
}

\author{
Michelle Edmonds ${ }^{1}$ \\ ${ }^{1}$ School of Nursing, Jacksonville University, United States \\ Correspondence: Michelle Edmonds, School of Nursing, Jacksonville University, United States. E-mail: \\ medmond@ju.edu
}

Received: January 30, 2013 Accepted: February 18, 2013 Available online: March 21, 2013

doi:10.11114/jets.v1i1.56

URL: http://dx.doi.org/10.11114/jets.v1i1.56

\begin{abstract}
Recruitment of nursing students is not the issue. Each year, nursing programs across the country turn away highly qualified applicants due to faculty shortage and limited clinical space. Therefore, it is imperative to retain those who secure one of these valuable spots as a nursing student. An "Introduction to Nursing" course was offered to pre-nursing freshman at one university for the purposes of increasing nursing student retention, rather than recruitment. This study examined the impact of an "Introduction to Nursing" course from a qualitative descriptive perspective. Participants reported three themes: orienting, connecting, and validating that occurred as a result of taking this course. Results indicate that both the student and the nursing program benefit as a result of offering this course. Students are provided with a realistic perspective of the nursing program and profession while the nursing program admits more informed students with less potential for voluntary attrition.
\end{abstract}

Keywords: pre-nursing, nursing education, retention, attrition, nursing shortage, introduction to nursing

\section{Introduction to the Problem}

Recruitment of nursing students is not the issue. Each year, nursing programs across the country turn away highly qualified applicants due to faculty shortage and limited clinical space. Therefore, it is imperative to retain those who secure one of these valuable spots as a nursing student. An "Introduction to Nursing" course was offered to pre-nursing freshman at one university for the purposes of increasing nursing student retention, rather than recruitment. It was noted that a permanent attrition of two to five nursing students (or 2.5-6\%) would result early in the first nursing courses as students decided that nursing was not the major they intended to pursue for various reasons (i.e. thought it would be an easy major, doing it for their parents rather than self, wanted to make money and have a stable occupation). This voluntary attrition, or choice to pursue a major other than nursing, is considered permanent because these students accepted a position and then failed to complete the first nursing courses. It was often too late into the semester to enroll a student from the waiting list. This study examined the impact of an "Introduction to Nursing" course from a qualitative descriptive perspective.

\section{Purpose of the Study}

The purpose of this study was to examine the impact of an "Introduction to Nursing" course. It was assumed that students who took this course would have received benefits over those who did not take this course. It was also speculated that nursing programs would be indirect recipients of these benefits by having a better prepared student and one that was less likely to voluntarily withdraw.

\section{Research Question}

The research question was: What is the impact for nursing students who participated in an "Introduction to Nursing" course?

\section{Review of the Literature}

The nursing faculty shortage in the United States has been well documented. As a result, qualified students are turned away from nursing programs in large numbers. Sand-Jecklin \& Schaeffer (2006) noted that nursing programs cannot manage to lose students to withdrawal, whether voluntary or involuntary, if they expect to relieve the current nursing and faculty shortages. Therefore, it is vital that nursing student retention rates increase 
and attrition rates decrease.

Retention of nursing students can be achieved in a number of ways. If students receive support from their professors, they report being more motivated to progress toward graduation (Shelton 2003). Research conducted by Jeffreys (2007a, 2007b) has found similarly that faculty and peer mentoring provides support to at-risk students who are in their first semester of a nursing program and may have underestimated its rigorous requirements and demands. Faculty advisement, feeling included, and in-class peer friendships were a sense of support reported by these at-risk, non-traditional students (Jeffreys, 2007a, 2007b).

Likewise, if students entering a nursing program possess a realistic understanding of the profession, student satisfaction and retention to entry-level practice is achieved (Sand-Jecklin \& Schaeffer, 2006). Students who embrace a more stereotypical view of nursing were more likely to leave (Sand-Jecklin \& Schaeffer, 2006). Others have indicated that it is the ethical obligation for schools of nursing to provide insight to students regarding the expectations of their chosen profession in nursing (Crow, Hartman \& McLendon, 2009; Karaoz, 2004). Ideally, this should begin at the recruitment phase along with the realistic demands imposed by the nursing curriculum (Hayes, 2007; Wells, 2007).

While there are noted few studies examining American student perceptions of the profession of nursing (Sand-Jecklin \& Schaeffer, 2006), Karaoz (2004) explored this phenomenon with Turkish nursing students. Once students completed their initial nursing course, their perspective of the professional nursing role had been broadened far beyond the stereotypical view often portrayed in the media (Karaoz, 2004).

\section{Significance of the Study}

The significance of this study lies in the gap of current nursing knowledge on the topic of "Introduction to Nursing" courses for pre-nursing students. Some institutions of higher education offer a course similarly titled, but usually targeted to students who have already been admitted to the nursing program. It is important to determine the benefits of offering a course such as this to students prior to entering the nursing program. This study sought and has begun to fill that need.

\section{Method}

This retrospective, qualitative descriptive study received Institutional Review Board (IRB) approval through the university. Audio-recorded interviews were arranged with the willing participants who met the inclusion criteria. Participants were asked a series of semi-structured questions, leaving plenty of time for free expression of their own thoughts and ideas. Questions were asked of all participants regarding motivation to take the "Introduction to Nursing" course, personal self-discoveries that occurred during the course, feelings about the nursing profession, and if they would recommend this course to future pre-nursing students. Ethical principles of research were closely guarded throughout the entire data collection process, including ensuring that the researcher was not also the current teacher for any of these participants and keeping all data collection materials confidential and secure. The researcher was also the instructor for this "Introduction to Nursing" course. Therefore, every effort was made to bracket for preconceptions and ensure that none of the research participants were also her current students. The researcher then created a verbatim transcript after each audio-taped interview and immediately began the iterative data analysis process, examining the data for common themes. Once data analysis was completed, the researcher sent the individual transcript and constructed themes to each participant for member checks, thus providing validity and reliability of the findings.

\section{Demographics of Sample}

The sample was purposively selected in accordance with the qualitative method from a small, private liberal arts university in the Southeastern United States that has had a nursing program for over 25 years. The undergraduate nursing program graduates approximately 65-80 Bachelor of Science in Nursing (BSN) students annually. The inclusion criteria for this study were that the participant needed to be English-speaking, at least 18 years of age, and currently enrolled in a nursing program. In addition, they needed to have been enrolled and have completed the "Introduction to Nursing" course in either fall 2007 or fall 2008, the first and second years respectively that this course was taught. Approximately 20 students took this course in 2007 and again in 2008; however, not all 40 of these students who took the "Introduction to Nursing" course were admitted to the nursing program during the competitive admissions process. The participants were considered exempt from the study if they did not meet the inclusion criteria or were a current student of the researcher. Approximately 20 students meeting the inclusion criteria were invited to participate in the study via personal email communication. Six of the 20 agreed to participate and be interviewed. The other fourteen who did not respond to this invitation to participate in the research study were similar in demographics as the actual participants. 
The sample $(\mathrm{N}=6)$ was very young at the time of the study with three of the participants who reported their age as 19 years. Two of the other participants were 20 years old and one participant was 21 years old. The participants were one to two years younger when they actually took the "Introduction to Nursing" course. For most, if not all, it was one of their first semester freshman courses so they were only about three to four months out of high school when they were students in the course.

The majority $(83 \%)$ of the participants were female with only one male in the sample. Four of the participants reported their current academic level as a junior and 2 were sophomores. The juniors are considered second-year nursing students and would have completed approximately 12 - 15 semester credits in nursing. The sophomores are first-year nursing students and would have completed only six semester credits in nursing at the time of the study. None of the sample had actually completed the nursing curriculum.

All of the participants in the study were single (not married) and all were freshman by credit hour when they took the "Introduction to Nursing" course. Additionally, all participants reported their ethnicity as Caucasian except for the male who reported his ethnicity as Asian and African-American.

\section{Intervention}

An "Introduction to Nursing" course was offered for the first time to pre-nursing students, primarily freshman, in the fall of 2007. This course was designed as an effort to decrease attrition rates as opposed to a tool to increase recruitment. This School of Nursing has approximately three to five qualified applicants for every nursing student position and therefore does not need to increase recruitment. However, it was anecdotally noted over the prior five years that very qualified students would enter the pre-licensure nursing program and drop the major within the first six weeks, too far in to replace them with another student on the waiting list. Unlike attrition due to failure who have the potential of re-entering, this attrition due to voluntary withdrawal early in a program is a permanent attrition and often unrecoverable unless they are replaced with students transferring from another nursing program. This change of major was often not due to failure but rather a misunderstanding of the nursing profession. Some students would often comment that they thought nursing would be an easy major and promptly realized that this was not the case. Others did not have a realistic impression of the nursing role and how they would provide often intimate care of strangers or were pursuing this major to please parents rather than themselves. The "Introduction to Nursing" course evolved as a way to give the pre-nursing students a sampling of things to come as both a nursing student as well as a practicing nurse.

The course was developed by a nursing professor and has been taught every fall since its inception by the same faculty. It is offered as a one-credit elective course for pre-nursing majors - those students who have not yet been accepted to begin the nursing program. It currently a required course only for the students in the freshman nursing cohort, a program for qualifying high school students who have a reserved position in the nursing program provided they perform to pre-determined standards during their freshman year. All students who successfully complete the "Introduction to Nursing" course receive one-credit toward their two-credit nursing elective requirement once they have been admitted as a Nursing student.

The course met approximately one hour each week. A multitude of topics were discussed including but not limited to:

- $\quad$ history of modern professional nursing and the work of Florence Nightingale

- $\quad$ nursing education and various degrees in nursing

- $\quad$ stress management and burnout in nursing

- licensure/certification in nursing and belonging to professional nursing organizations

- $\quad$ various nursing roles

- $\quad$ nursing on the front lines and disaster preparedness

- $\quad$ nursing and faculty shortage

A textbook was used supplemented by various articles and internet sources. Students worked in groups to present the bulk of this content to the class. This provided an engaged learning atmosphere, allowed the students to be well-informed of one particular topic, and provided them a preview to the type of work expected of them once they entered the nursing program. Clarification from the course facilitator was offered as needed. Additionally, the course facilitator solicited the help from fellow colleagues in the School of Nursing to attend the class sessions as guest speakers about a particular nursing role. These guest speakers served several purposes. Students could hear about a multitude of nursing roles including mental health, women's health and obstetrics, pediatrics/neonatal, emergency, surgical, critical care, administration, etc. Students also had the opportunity to 
meet the faculty who may become their future professors in the nursing program. This guest lecturing by the nursing faculty was more of an informal time of questions/answers about one's journey in nursing rather than a formal presentation. Finally, student speakers were recruited to come during one class and offer a "How to Survive Nursing School" session. The course facilitator is present again for clarification but it is an engaging opportunity for interaction between the experienced senior nursing students and the pre-nursing students. This is often one of the most memorable experiences throughout the entire course in which they can have their questions answered and be offered pearls of wisdom from those who have been there, done that!

Students in the "Introduction to Nursing" course complete assignments modeled after those required of the nursing majors. Each class session, they complete one-minute papers summarizing key points from the class which are posed in question form by the instructor. In addition to the group presentation previously mentioned, the students also complete a paper on a nursing role of their preference, researching topics such as pros/cons, salary, licensure/certification, education requirements, and more. Finally, students compose a written reflection after they complete a three-hour observation experience with a practicing nurse in a clinical setting. They respond to guided questions about their experience and summarize as to whether or not they will continue to pursue nursing as their major.

\section{Results}

Since its implementation in the fall 2007 semester, the nursing program has boasted an $80 \%$ retention rate of students who have completed this course. While the majority of the $20 \%$ attrition was due to failure in the nursing curriculum, a few of these students had life changes causing them not to pursue the nursing major. None of these students reported their exit from the nursing program was due to lack of knowledge or interest in the nursing profession.

As a result of taking the "Introduction to Nursing" course, three essential themes became evident in the data analysis of the participants' verbatim transcripts: orienting, connecting, and validating.

Orienting was the theme that described the familiarity the students gained with the expectations of nursing school and the role of the professional nurse. This orienting was achieved through active and passive opportunities. Pre-nursing students had active opportunities to familiarize themselves with the expectations of a rigorous nursing program by completing assignments modeled after those expected of a nursing major. Likewise, they had passive opportunities to become oriented to the role of a nursing student and practicing nurse through guest speakers such as the nursing faculty and senior nursing students.

The theme of orienting was expressed by one of the participants as "an intro to nursing class...taught by the school. It was nice knowing what you were kinda getting into. Get an overview of what was going to go on in like the whole nursing school" and "meeting the professors and then being in the class, having little projects, being in the hospital...you kinda get a taste of what it's going to be like!" Another student candidly described "I didn't really have any clue of what nursing was like ... actually learning about a profession in a book or someone telling you is a whole lot different than seeing what they do...being in the hospital and doing the shadow experience before you're actually having to go to clinicals did make me a little less nervous to be in the clinical setting, the very first day." The one male participant remarked:

"I thought nursing was just the whole white hat, and white skirts. Sitting at the bedside of the patient. But there's a lot more than that. So there's a wider variety than I had in mind...I was narrow minded when I came to nursing. And this really opened me up and put a broader spectrum for it... I would say it was a good foundation since I didn't know what I was going to expect. But I thought, OK, at least I have a base! And now that I'm in the program...I feel like there's a safety net that was established in that class for nursing school!...so I felt like I was prepared and I was forewarned that you have to work hard, you have to be diligent, persistent in what you do!"

Connecting was expressed by participants as both a physical and emotional connection to nursing. Connecting was a very active theme that explained the formation of relationships with peers who would become future classmates in the nursing program. Also, to a lesser degree, connecting described the bonds created with the nursing faculty and senior nursing students. Finally, the participants reported a connection to the physical nursing building itself and how that instilled a sense of comfort later when they entered the nursing program.

One student explained connecting as "it was kinda nice meeting the people you're going to be with... in the same class. I'm still friends with some of the people that I met in there [Introduction to Nursing course]." A similar sentiment was recalled by this student:

"I'm still in class with and am friends with and it kind of establishes a support base not only for the 
interviews getting into the program and excitement about that but continuing on into the classes. It was nice to get to know some of the teachers cause then you don't feel so intimidated. It's really intimidating when you start cause it's so hard, and you hear that it's really hard but having that good first experience...makes it kind of easier going into the first semester of classes where you have to work really hard."

Another participant remarked:

"I mean I think it's nice to be in the atmosphere and kinda get a feel for it before you actually begin it [nursing program]. I know people who didn't take the intro course and they were like a little more confused about the...even the application process or more scared to visit the nursing building. They feel like if you weren't a nursing major you can't enter the building. I think it was a good way before you're an actual nursing student to get acquired to the environment of the nursing building and get used to the nursing staff (faculty) so you're a little less anxious and scared when you actually do."

Finally, the theme of validating occurred toward the end of the "Introduction to Nursing" course in which students finalized their decision to pursue nursing as their major after a thorough appraisal of its requirements. One student exemplified the theme of validating when she noted "There was like a video or something that we watched in class...talked about how you're going to...save people's lives and watch people die and just be there for people that really stuck in my mind and I just knew at that point... it's gonna be good and it's gonna be bad but I really wanted to go through both of those and it was going to be gratifying in the end." Another participant commented that a course like this could reduce attrition:

"the course actually did make me definite to nursing through like the shadow experience like having to research more into the nursing role... and just learning the basics of what would be expected...helped me to decide that maybe it would be a good fit for me...cause I know people that got in and dropped out or got in and were like "I don't want to be a nurse!" and could be because either they didn't take this course and have an opportunity to know about it or be aware."

Another participant echoed this sentiment:

"it was definitely intimidating...made me take a step back and question myself if I have enough intelligence to get through this program? And it definitely makes you look at what you're capable of. And that's what I liked about the class... [the shadow experience] is just another indication that's what I really wanted to do!....[the Introduction to Nursing course] prevents a lot of drops. It'll be more beneficial the following year when they make it into the program and decide they don't want to do it. They put all this work into the application and then all the books and everything. They'd have to repeat semesters and stay longer... and probably wouldn't graduate on time."

\section{Implications for Nursing Education, Research, and Practice}

The findings from this study have the most direct implications for nursing education. Offering a course such as this for pre-nursing students is a win-win scenario for both students and nurse educators. Students receive a realistic preview of not only the nursing program but also the nursing profession. They also receive a tangible benefit in the form of elective nursing credit toward their nursing major and assistance with special advisement about the application process that they might not otherwise. Students also have the opportunity to meet the faculty, complete assignments modeled after those given to a nursing major, and have an opportunity to observe a practicing nurse in a clinical setting. Finally, they have the benefit of learning pearls of wisdom from experienced and successful nursing students. In addition, nurse educators also benefit from having a preview of the potential upcoming nursing students and the confidence that these students have received a realistic preview in an effort to reduce attrition by preventing voluntary withdrawals.

A natural extension of keeping more students in the seats and retaining them to graduation provides an implication for nursing practice. If students are satisfied, retained, and operating from a realistic preview of the nursing profession, they will graduate and help provide immediate relief of the current nursing and, in due time, the nursing faculty shortage.

The implications for nursing research are vast. "Introduction to Nursing" courses need to be implemented and evaluated on a larger scale to assess long-term impact. Future qualitative and quantitative studies are necessary to investigate the benefits for students as well as nursing programs.

\section{Limitations and Recommendations of the Study}

The following limitations of this study have been identified. The sample was small and homogenous as far as 
demographic characteristics. In addition, the possibility of biased recall might have been present in the notion that these participants were successful current nursing students, closely connected to their professors, course content, and fellow students. However, despite its small size, the essential themes were well-supported in the data collected but would need to be validated by further qualitative inquiry. A recommendation would be to replicate this study including a larger sample with more diverse demographic characteristics and include a longitudinal design. Another limitation is the recognition that qualitative findings are not able to be generalized beyond this one unique sample. Furthermore, this sample was derived from one small, private liberal arts university in the Southeastern United States. Students may have been well-known to each other and the researcher. A recommendation would be to replicate this study in a different region of the United States and a different type of university.

\section{Conclusion}

The findings from this study are consistent with the current literature on reducing attrition by providing a realistic preview of the profession and removing misconceptions or stereotypes. In conclusion, this study provided valuable information where the nursing literature is currently lacking. An "Introduction to Nursing" course can provide an engaged learning opportunity in which students become familiar with the program of study and profession of nursing. Participants had the opportunity to validate their decision to pursue nursing as their major after careful self-reflection and appraisal. Students who successfully completed this course reported feeling a close connection to the nursing program and faculty as well as to each other. In addition, they acquired realistic perspective of the rigorous demands of being a nursing major and eventually a practicing nurse. Overall, these benefits may provide a much needed answer to reducing attrition through voluntary withdrawal in nursing programs.

\section{References}

Crow, S. Hartman, S., \& McLendon, C. (2009). The realistic job preview as a partial remedy for nursing attrition and shortages: The role of nursing schools. The Journal of Continuing Education in Nursing, 40(7), 317-323. http://dx.doi.org/10.3928/00220124-20090623-06

Hayes, L. (2007). Recruitment strategies for Baccalaureate nursing students in Ontario. Journal of Nursing Education, 46(6), 261-268.

Jeffreys, M. (2007a). Nontraditional students' perceptions of variables influencing retention: A multisite study. Nurse Educator, 32(4), 161-167. http://dx.doi.org/10.1097/01.NNE.0000281086.35464.ed

Jeffreys, M. (2007b). Tracking students through program entry, progression, graduation, and licensure: Assessing undergraduate nursing student retention and success. Nurse Education Today, 27, 406-419. http://dx.doi.org/10.1016/j.nedt.2006.07.003

Karaoz, S. (2004). Change in nursing students' perceptions of nursing during their education: The role of the Introduction to Nursing course in this change. Nurse Education Today, 24, 128-135. http://dx.doi.org/10.1016/j.nedt.2003.10.010

Sand-Jecklin, K. \& Schaeffer, A. (2006). Nursing students' perceptions of their chosen profession. Nursing Education Perspectives, 27(3), 130-135. http://dx.doi.org/10.1043/1094-2831(2006)027[0130:NSPOTC]2.0.CO;2

Shelton, E. (2003). Faculty support and student retention. Journal of Nursing Education, 42(2), 68-76.

Wells, M. (2007). Dreams deferred but not deterred: A qualitative study on undergraduate nursing student attrition. Journal of College Student Retention, 8(4), 439-456. http://dx.doi.org/10.2190/17K2-5847-6637-L70P

\section{(cc) EY}

This work is licensed under a Creative Commons Attribution 3.0 License. 